\title{
DETERMINAÇÃO DE CARBARIL UTILIZANDO TESTES ELISA (ENZYME-LINKED IMMUNOSORBENT ASSAY) E CLAE COM DETECÇÃO POR ARRANJO DE DIODOS
}

Ilda A. S. Toscano*, M. Lúcia Ribeiro, Julio C. Rocha

Instituto de Química - Universidade Estadual Paulista - Rua Prof. Francisco Degni, s/n - 14800-900 - Araraquara - SP

Gilvanda S. Nunes

Departamento Química Tecnológica - Universidade Federal do Maranhão - Av. dos Portugueses, s/n - 65080-040 - São Luís - MA Damiá Barceló

Departamento Química Ambiental - Centro de Investigación y Desarrollo - c/ Jordi Girona - 18-26 - 08035 - Barcelona - Espanha.

Recebido em 13/5/99; aceito em 3/1/00

\begin{abstract}
DETERMINATION OF CARBARYL BY ELISA (ENZYME-LINKED IMMUNOSORBENT ASSAY) AND HPLC WITH PHOTODIODE ARRAY DETECTION. ELISAs have been applied to pesticide residue analysis due to their high sensitivity and selectivity. However, some ELISAs performance may be affected by matrix components. In this work, ELISA for carbaryl in water samples was checked for interference by naturally occurring fulvic acids. The results suggested that the high fulvic acid concentration $\left(\geq 30 \mathrm{mg} \mathrm{L}^{-1}\right)$ and acidic $\mathrm{pH}$ conditions (pH 4.0) interfere with the signal detection decreasing the method sensitivity. A dilution of the samples and adjust to pH 8.0 are appropriate to minimize the matrix interferences in the ELISA method. Good correlation between ELISA and HPLC-DAD results was observed.
\end{abstract}

Keywords: ELISA; carbaryl; fulvic acids.

\section{INTRODUÇÃO}

Grande parte da matéria orgânica contida no solo e em águas naturais encontra-se como substâncias húmicas (SH). Essas substâncias são uma mistura complexa de moléculas com alto peso molecular, semelhantes entre si e formadas pela decomposição biológica e enzimática de vegetais no solo ${ }^{1}$. São transportadas às águas naturais por processos de lixiviação, e/ou podem também ser formadas diretamente no meio aquático por decomposição de plantas e organismos aquáticos. O interesse por substâncias húmicas aquáticas (SHA) deve-se ao papel desempenhado por elas nos ecossistemas aquáticos em razão da multiplicidade de grupos funcionais comuns, por exemplo, fenólicos e carboxílicos os quais são responsáveis pela excepcional reatividade do material ${ }^{2,3}$.

A definição operacional de SHA está baseada nos métodos de extração e são classificadas em termos de solubilidade em soluções ácidas e básicas. Ácidos húmicos (AH) são a fração de $\mathrm{SH}$ insolúvel em $\mathrm{pH}<2$; ácidos fúlvicos (AF) são a fração solúvel em todo intervalo de $\mathrm{pH}$. Thurman \& Malcolm ${ }^{4}$ definiram SHA como a porção não específica, amorfa, constituída de carbono orgânico dissolvido (COD) em pH 2,0 e adsorvível em coluna recheada com resina XAD 8 com altos valores de coeficiente de distribuição. A matéria orgânica retida pela resina é eluída com solução de $\mathrm{NaOH} 0,1 \mathrm{~mol} \mathrm{~L}^{-1}$, obtendo-se assim, o extrato alcalino de material orgânico chamado de SHA.

As interações das $\mathrm{SH}$ com compostos orgânicos antropogênicos, por exemplo os pesticidas, estão relacionadas com efeitos de adsorção, efeitos solubilizantes, hidrólises, processos microbiológicos e fotossensibilizantes ${ }^{5}$. O efeito solubilizante do material húmico sobre compostos orgânicos pode desempenhar importante papel na dispersão, mobilidade e transporte desses produtos no ambiente aquático ${ }^{6,7}$. Estudos de fotodegradação de pesticidas carbamatos sugerem que os ácidos húmicos atuam como catalisadores, aumentando a velocidade de degradação dos pesticidas ${ }^{8}$.

e-mail: ilda@labpesq.quimica.ufpb.br
A determinação de pesticidas em águas naturais, solos e sedimentos geralmente é complexa, exigindo várias etapas de extração e clean-up das amostras, além de equipamentos sofisticados, tornando a análise cara e demorada. Isto é devido às etapas de purificação e, às vezes, à necessidade de derivatização dos compostos a serem analisados ${ }^{9,10}$. Em decorrência da intensa aplicação de pesticidas e da crescente conscientização social, muitos programas de vigilância e controle cada vez mais rigorosos estão surgindo. Para tal, é necessário o uso de técnicas menos laboriosas, que permitam a análise de um grande número de amostras e que, se possível, sejam feitas o mais perto do local de coleta. Embora muitos métodos cromatográficos continuem predominando, novas metodologias para análise de resíduos de pesticidas em amostras ambientais vêm sendo desenvolvidas rapidamente nos últimos 10 anos ${ }^{11,12}$. Nesse aspecto, as técnicas imunoquímicas (imunoensaios) e as que empregam os biossensores estão sendo muito utilizadas. As razões da demanda são a alta seletividade, fácil manuseio e a sensibilidade, que pode chegar a partes por bilhão $\left(\mu \mathrm{g} \mathrm{L}^{-1}\right)$ e até mesmo a partes por trilhão $\left(\mathrm{ng} \mathrm{L}^{-1}\right)^{13,14}$.

Existem vários tipos ou formatos de imunoensaios e um deles, enzyme-linked immunosorbent assay, ELISA, está sendo cada vez mais utilizado para quantificação de pesticidas, como técnica complementar aos métodos cromatográficos tradicionais. Por apresentarem alta seletividade e sensibilidade, os testes ELISA, baseados na reação entre antígeno e anticorpo, podem ser adequados à análise de contaminantes orgânicos em vários tipos de amostras ${ }^{15,16}$. Uma das vantagens é que os testes ELISA podem ser feitos in situ e para um grande número de amostras simultaneamente. Vários estudos mostram excelente correlação com os resultados obtidos por cromatografia e por ELISA ${ }^{17}$. Entretanto, por se tratar de uma técnica nova, há necessidade de se avaliar a aplicabilidade do método para diversos tipos de amostras ambientais ${ }^{18,19}$.

Um ensaio imunoquímico só pode ser considerado totalmente otimizado após minucioso estudo dos efeitos exercidos por alguns parâmetros físico-químicos sobre seu funcionamento. $\mathrm{O}$ aspecto mais importante, é que estes efeitos podem ser minimizados, ou eliminados, obtendo-se ensaios com ótima 
sensibilidade $\left(\mathrm{ng} \mathrm{L}^{-1}\right)$. Neste sentido, os principais objetivos deste trabalho foram: $i$ ) avaliar a influência (efeito matriz) das SHA na determinação do pesticida carbaril utilizando testes ELISA; ii) avaliar a influência da luz solar e presença de húmicos na formação do 1-naftol, principal produto de transformação do carbaril.

\section{MATERIAIS E MÉTODOS}

\section{Amostra}

Amostra de água superficial foi coletada do córrego Itapitangui localizado na bacia 54 - Ribeira do Iguape, município de Iguape, litoral sul do estado de São Paulo. Após coleta, a amostra foi acidificada até $\mathrm{pH} 2,5$ com solução de $\mathrm{HCl}$ e armazenada em frascos plásticos. Antes da extração, a amostra foi filtrada em papel qualitativo para remoção de sólidos e partículas suspensas. Em seguida, cerca de 330 litros de água foram passados, por gravidade, a uma vazão de $4 \mathrm{~mL} \mathrm{~min}^{-1}$ através de colunas de vidro, dispostas em série, contendo as resinas XAD 7 e XAD 2 (Serva Feinbiochemica Gmbh \& Co, Germany $)^{20}$. O material orgânico foi eluído com solução de $\mathrm{NaOH} 0,1 \mathrm{~mol} \mathrm{~L}^{-1}$ e posteriormente acidificado até $\mathrm{pH} 1$ para o fracionamento em $\mathrm{AH}$, que precipitam, e em $\mathrm{AF}$ que permanecem em solução. As frações de $\mathrm{AH}$ e AF foram dialisadas contra água Milli-Qplus (Millipore, Molsheim, France) e liofilizadas, obtendo-se 14,0 g de AF e 4,0 g de AH. Neste trabalho, utilizou-se a fração AF.

\section{Análise cromatográfica do carbaril}

Todos os solventes utilizados foram de grau resíduo (Mallinckrodt), previamente filtrados em membranas de $0,45 \mathrm{~mm}$ de diâmetro de poro. A água deionizada foi de grau Milli- ${ }^{\circledR}$, produzida a $18,2 \mathrm{M} \Omega \mathrm{cm}^{-1}$. Para a eluição cromatográfica, utilizou-se também água grau CLAE (Merck). As soluções de carbaril foram preparadas a partir de um padrão de referência certificado $(99,4 \%$ de pureza, $\mathrm{MM}=201$, Dr. Ehrenstorfer, Alemanha). Uma solução estoque $\left(1000 \mathrm{ng} \mu \mathrm{L}^{-1}\right)$ foi preparada a partir da dissolução de quantidade exata do princípio ativo em metanol. As soluções de trabalho (entre 0,001 e $20,0 \mathrm{ng} \mu \mathrm{L}^{-1}$ ) foram preparadas imediatamente antes do uso, a partir da diluição da solução estoque com metanol a um volume apropriado. O mesmo procedimento foi adotado para o preparo das soluções estoque e de trabalho do 1-naftol $(99,8 \%$ de pureza, $M M=144$, Dr. Ehrenstorfer, Alemanha).

Para as análises cromatográficas, foi utilizado um sistema cromatográfico Waters CLAE, consistindo de uma bomba quaternária (modelo 600-MS), acoplada a um detetor por arranjo de diodos (AD) Waters ${ }^{\mathrm{TM}}$ (modelo 996, Milford, MA, Estados Unidos), e um sistema injetor do tipo Rheodyne de volume fixo de $20 \mu \mathrm{L}$ (California, Estados Unidos). A coluna cromatográfica utilizada foi de aço inoxidável, em fase reversa, Zorbax SB-C 18 (Rockland Technologies Inc., Holanda) de 15 $\mathrm{cm} \times$ 4,6 mm d.i., recheada com partículas de $5 \mu \mathrm{m}$ de diâmetro. Como fase móvel utilizou-se mistura de acetonitrila-água a uma vazão de $1,0 \mathrm{~mL} \mathrm{~min}{ }^{-1}$, com programação de gradiente para decréscimo de polaridade, com variação de 20 até $100 \%$ de acetonitrila em $20 \mathrm{~min}$. O comprimento de onda utilizado, o de máxima absorção do composto, foi de $200 \mathrm{~nm}$.

\section{Imunoensaio ELISA para carbaril}

Os ensaios ELISA foram feitos em placas de poliestireno com 96 cavidades de base cônica (Nunc, Maxisorb), recobertas com fitas adesivas de acetato de 8,3 x 13,3 cm. Pipetas multicanais automáticas de vários volumes, de $0,5 \mu \mathrm{L}$ até $1000 \mu \mathrm{L}$, microtubos e cubetas de poliestireno foram utilizados para o preparo de soluções e transferência de volumes. Lavador de placas (SLT 96PW) e um leitor de placas (fotômetro Multikskan Plus MK II) também foram empregados. Todas as soluções-tampão foram preparadas em água deionizada. Sais, ácidos e peróxido de hidrogênio foram de grau analítico (Merck).

Os imunoreagentes e demais soluções foram preparadas como descrito abaixo:

1. Solução estoque de carbaril a $10 \mathrm{mmol} \mathrm{L}^{-1}$. Preparada por dissolução do padrão em dimetilsulfóxido (DMSO) e armazenada a $4^{\circ} \mathrm{C}$; soluções de trabalho $\left(1 \mathrm{nmol} \mathrm{L} \mathrm{L}^{-1}\right)$, por diluição da solução estoque com DMSO antes do uso.

2. Curva padrão para carbaril. Uma diluição seqüencial (fator 1:5) da solução de trabalho $\left(1 \mathrm{nmol} \mathrm{L}^{-1}\right)$ foi efetuada, de modo a obter concentrações variando de $25.10^{3}$ até $1,3.10^{-2} \mathrm{nmol} \mathrm{L}{ }^{-1}$ do pesticida.

3. Anticorpo policlonal anti-carbaril e antígeno de recobrimento. Os imunoreagentes foram fornecidos pelo Prof. Dr. Bruce D. Hammock do Departamento de Entomologia da Universidade da Califórnia, Davis, USA. O anticorpo policlonal R2114 foi extraído do soro de coelhos imunizados com 8-KLH, obtido da reação de conjugação entre (1-(5 carboxipentil)-3-(1-naftil) uréia e a proteína keyhole limpet hemocyanin (KLH). O antígeno de recobrimento, 5-CONA, foi sintetizado pelo acoplamento covalente do ácido $N$-(2-naftol)-6-amino-hexanóico com a proteína conalbumina (CONA). A síntese destes compostos foi previamente descrita por Marco et al. ${ }^{21}$.

4. Anti-anticorpo de coelho. Extraído de cabra [Goat antirabbit - IgG-horseradish peroxidase (Anti-IgG-HRP)], fornecido por Sigma (catálogo número R2004, St. Louis, MO).

5. Substância cromógena. TMB 0,6\% (3,3',5,5'-tetramethylbenzidina) em DMSO.

6. Tampão de recobrimento. Solução tampão de carbonato $(\mathrm{pH}$ 9,5) preparada por dissolução de $\mathrm{Na}_{2} \mathrm{CO}_{3}(0,795 \mathrm{~g})$ e $\mathrm{NaHCO}_{3}(1,465 \mathrm{~g})$ em $500 \mathrm{~mL}$ de água.

7. Tampão PBS (solução salina tamponada, $\mathrm{pH} 7,5$ ). Preparada por dissolução de $\mathrm{NaCl}(8 \mathrm{~g}), \mathrm{KCl}(0,2 \mathrm{~g}), \mathrm{KH}_{2} \mathrm{PO}_{4}(0,2$ g) e $\mathrm{Na}_{2} \mathrm{HPO}_{4}(1,15 \mathrm{~g})$ em $1 \mathrm{~L}$ de água.

8. Tampão do imunoensaio, PBST (também usado como solução de lavagem). Solução de PBS, contendo $0,5 \%$ Tween 20 (Sigma).

9. Mistura substrato-cromógeno. Preparada imediatamente antes do uso, misturando-se $400 \mu \mathrm{L}$ TMB, $100 \mu \mathrm{L} \mathrm{H}_{2} \mathrm{O}_{2}$ $1 \%$ e $25 \mathrm{~mL}$ de tampão citrato-acetato (pH 5,5).

10. Solução de interrupção da reação. A reação enzimática foi interrompida por adição de solução de $\mathrm{H}_{2} \mathrm{SO}_{4} 4 \mathrm{~mol} \mathrm{~L}^{-1}$.

\section{Protocolo ELISA para carbaril}

Inicialmente, as cavidades das placas foram cobertas com $100 \mu \mathrm{L} /$ cavidade da solução de antígeno $(0,4 \mu \mathrm{g}$ 5-CONA por $\mathrm{mL}$ de tampão de recobrimento), seguida por incubação durante uma noite a $4^{\circ} \mathrm{C}$. Amostras reais ou fortificadas e as soluções padrão (curva de calibração) foram pré-incubadas a $4^{\circ} \mathrm{C}$ com o anticorpo policlonal R2114 (diluição 1/32000 (v/v) em PBST) em microtubos. Após o período de incubação, um volume de $100 \mu \mathrm{L}$ dessas soluções (amostras e padrões) foram adicionadas a cada cavidade da placa, previamente lavada com tampão PBST, permanecendo em repouso por $30 \mathrm{~min}$ à temperatura ambiente. Em seguida, foram adicionados $100 \mu \mathrm{L}$ de anti-IgG-HRP (anticorpo anti-IgG, 1/6000 (v/v) em PBST) a cada cavidade. Após 1 hora de repouso, a placa foi lavada com PBST e $100 \mu \mathrm{L}$ da solução de substrato-cromógeno foram adicionados. A reação enzimática (desenvolvimento de coloração) foi interrompida com adição de $50 \mu \mathrm{L} /$ cavidade da solução de $\mathrm{H}_{2} \mathrm{SO}_{4}$ a $4 \mathrm{~mol} \mathrm{~L}^{-1}$ após 30 min de reação. As absorbâncias foram imediatamente lidas a $450 \mathrm{~nm}$. As concentrações do antígeno de recobrimento e do anticorpo policlonal foram previamente otimizadas por meio de um experimento 2D, descrito a seguir. A Figura 1 apresenta as estruturas dos imunoreagentes usados nesse trabalho, bem como um esquema do formato ELISA desenvolvido. 

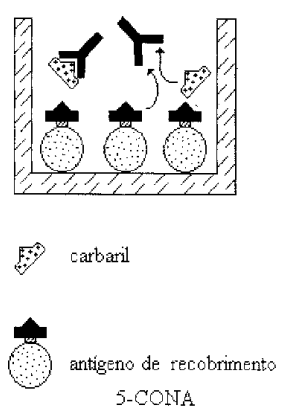

Tenticorpo E2114

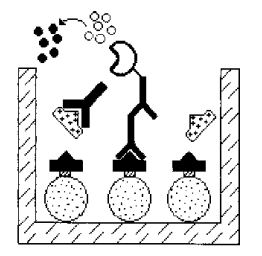

2) $2^{\circ}$ anticotpo ant

88 substrato

$\mathrm{TMB}-\mathrm{H}_{2} \mathrm{O}_{2}$

: produtos coloridos
Figura 1. Esquema do imunoensaio ELISA para análise de carbaril.

\section{Experimento 2D}

Após seleção dos imunoreagentes (anticorpo e antígeno), as soluções-estoque foram preparadas e, em seguida, acondicionadas a $-20^{\circ} \mathrm{C}$. As soluções de trabalho foram preparadas antes do uso, e guardadas em geladeira por no máximo uma semana. À medida que os imunoensaios iam sendo realizados, como se tratam de soluções biológicas, estas tenderam a perder sua atividade com o tempo. Assim sendo, um experimento paralelo em duas dimensões (Experimento 2D) foi realizado, aplicando-se o mesmo imunoensaio, e utilizando-se diferentes concentrações do antígeno e diferentes diluições do anticorpo. Evidentemente, com o tempo de uso, as quantidades utilizadas dos dois imunoreagentes tenderam a aumentar para garantir a sua eficiência. Para exemplificar, na Figura 2 têm-se as típicas curvas para estabelecimento desses valores de concentrações, utilizando-se os mesmos imunoreagentes, no primeiro dia de preparo da solução estoque (Figura 2a), e após 30 dias (Figura 2b). As melhores concentrações foram aquelas que, ao final do ensaio, a absorbância encontrada foi de 1,0. Para manter a eficiência do ensaio, o experimento $2 \mathrm{D}$ foi realizado mensalmente.

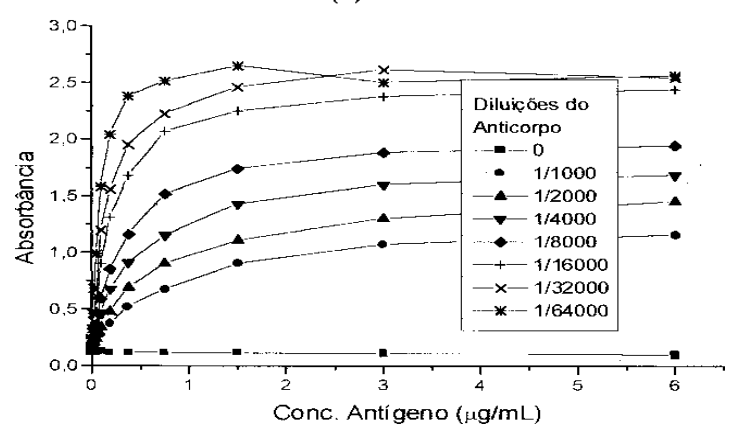

(b)

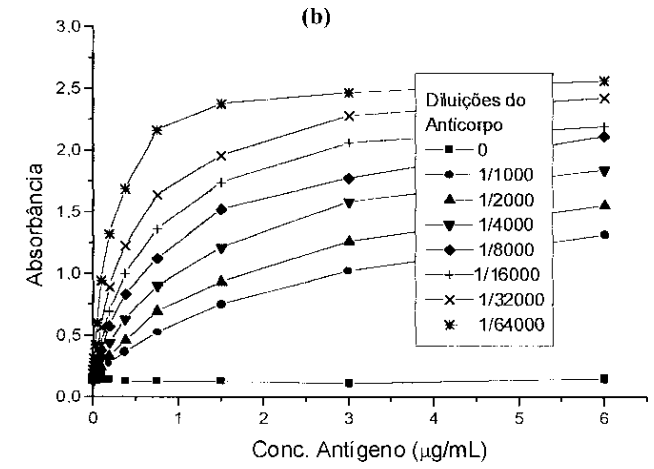

Figura 2. Experimento $2 \mathrm{D}$ (em duas dimensões) para determinação das concentrações do antígeno de recobrimento (5-CONA) e do anticorpo policlonal $R$ 2114. (a) 1 dia de preparo dos imunoreagentes; (b) 30 dias após o preparo dos imunoreagentes.

\section{Influência do pH e da concentração de ácidos fúlvicos}

Soluções de trabalho contendo 30,0 e $6,0 \mathrm{mg} \mathrm{L}^{-1}$ de AF e soluções controle (sem fúlvicos) em $\mathrm{pH}$ 4,0 e 8,0, foram fortificadas com solução estoque de carbaril, obtendo-se concentrações entre 0,001 e $20,0 \mathrm{ng} \mu \mathrm{L}^{-1}$. A análise do carbaril foi feita por ELISA.

\section{Influência da luz solar}

Alíquotas de $250 \mathrm{~mL}$, das soluções anteriormente descritas, foram colocadas em frascos Pirex com tampas plásticas. Uma série foi exposta às condições ambientais (luz solar e temperatura ambiente em torno de $25^{\circ} \mathrm{C}$ ) e outra foi mantida sob refrigeração a $4^{\circ} \mathrm{C}$ (ao abrigo da luz solar). Durante 120 minutos, a cada 10 minutos, foram retiradas alíquotas de $10 \mathrm{~mL}$ de todas as amostras para a quantificação de carbaril por ELISA e CLAE-AD. As amostras analisadas por CLAE-AD foram préconcentradas em cartuchos RP-18 (500 mg - LiChrolut Merck) e eluídas com DMSO, obtendo-se fator de concentração de $20 x$.

\section{RESULTADOS E DISCUSSÃO}

A análise de contaminantes orgânicos em solos e águas contendo altos teores de matéria orgânica, em especial material húmico, apresenta dificuldade adicional devido ao efeito matriz. Este efeito pode ser observado principalmente nas etapas de extração, pois o material húmico, sendo solúvel na maioria dos solventes utilizados, dificulta a remoção do analito da matriz. Quando se utiliza cromatografia líquida com detetor UV-VIS, o maior problema está na etapa final de detecção do analito, pois as substâncias húmicas absorvem fortemente abaixo de $400 \mathrm{~nm}$, mascarando o composto a ser determinado 9 . No caso de ensaios tipo ELISA, o sinal analítico é dado pela absorbância de produtos coloridos formados a partir das interações antígeno-anticorpo.

Fatores como a presença de cátions e ânions, tempo de reação, pH e conteúdo de matéria orgânica podem ser responsáveis pelo efeito matriz interferindo nas reações imunoquímicas. Em geral, o efeito matriz produz diminuição da intensidade de coloração (absorbância), levando a resultados errôneos, uma vez que o desenvolvimento de coloração é inversamente proporcional à concentração do analito ${ }^{22}$. Tal efeito pode ser devido à união não-específica do analito à matriz, união nãoespecífica da matriz ao anticorpo ou conjugado enzimático, ou ainda à desnaturação do anticorpo e/ou conjugado enzimático. As curvas de calibração são feitas com solução do antígeno em diferentes concentrações. Assim, obtém-se curvas "dose-resposta" do tipo sigmoidal com um intervalo linear de trabalho e a melhor sensibilidade. Em amostras ambientais, há uma tendência de superestimar a concentração do analito, determinada por ELISA quando comparado a métodos cromatográficos ${ }^{13}$.

Em estudos de otimização de ensaios ELISA, não se pode deixar de considerar que em amostras de águas reais são encontrados vários compostos, especialmente matéria orgânica que, de alguma forma, influem na determinação do analito. Por isto, neste experimento foram construídas curvas padrão (doseresposta) com amostras de AF fortificadas com carbaril, incluindo uma solução controle negativo. Quando uma amostra apresenta efeito matriz, que influencia fortemente a reação de competição de um ELISA, obtém-se curvas "dose-resposta" não paralelas às curvas padrão, sendo necessário então, um estudo adicional para desenvolvimento de um procedimento de preparação da amostra. $\mathrm{O}$ efeito matriz pode também ser avaliado pelo valor do coeficiente de inibição a $50 \%, \mathrm{IC}_{50}$, que é o parâmetro utilizado para se avaliar a reprodutibilidade e sensibilidade do método. Este valor representa a concentração de analito capaz de reduzir em 50\% a absorbância da solução controle negativo (padrão). 


\section{Influência do $\mathbf{p H}$ e concentração de AF}

Em ensaios ELISA, o pH do tampão influi tanto na sensibilidade como no sinal analítico (absorbância), principalmente durante a etapa de competição. Enquanto o paralelismo das curvas "dose-resposta" do padrão e das amostras se mantém, um deslocamento para a direita (perda de sensibilidade), ou para a esquerda (aumento de sensibilidade), indica a necessidade de se preparar curvas de calibração com a matriz ou introduzir uma etapa de purificação da amostra. Quando um efeito matriz influencia fortemente a reação de competição de um ELISA, obtém-se curvas "dose-resposta" não paralelas, sendo necessário então, otimizar-se o procedimento de preparação da amostra. Tal efeito pode ser visto na Figura 3, onde têm-se as curvas de calibração de carbaril em tampão PBST e em soluções de AF com concentrações de 6,0 e $30,0 \mathrm{mg} \mathrm{L}^{-1}$, em pH 4,0 e 8,0 , preparadas no momento da análise.

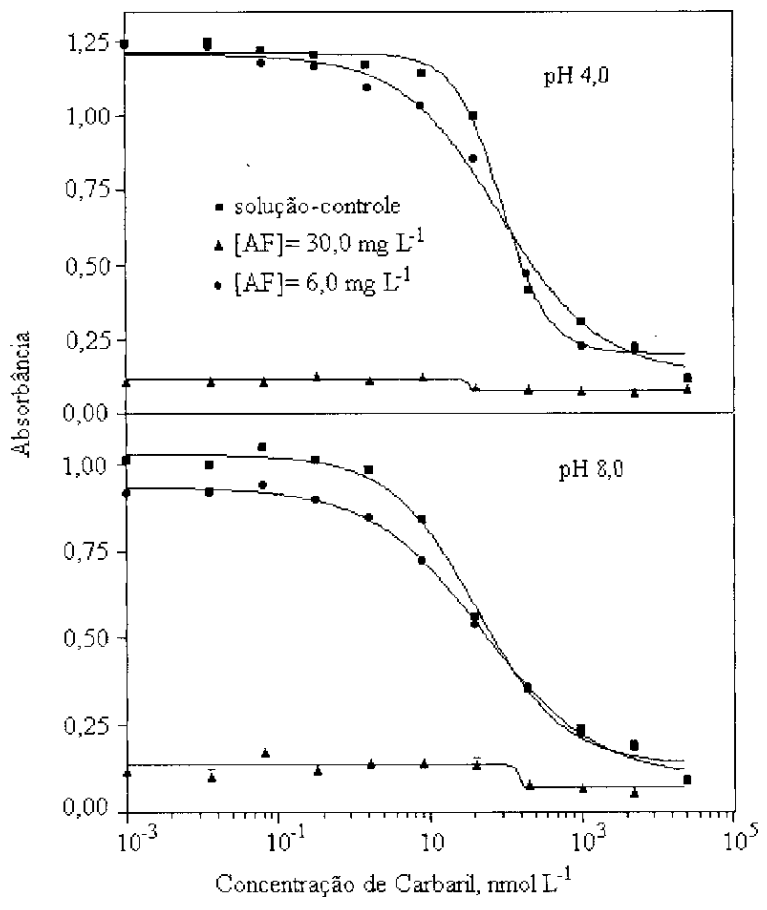

Figura 3. Influência do $\mathrm{pH}$ e da concentração de AF. Curvas de calibração de carbaril (25000 a 0,013 nmol $\left.L^{-1}\right)$ em solução-controle (tampão PBST 0,05\%, pH 7,5) e em soluções de AF $\left(6,0\right.$ e 30,0 $\mathrm{mg} \mathrm{L}^{-1} \mathrm{em}$ pH 4,0 e 8,0$)$.

Os formatos das curvas referentes às soluções de AF-carbaril indicam a forte influência da concentração de $\mathrm{AF}$, diminuindo a absorbância a valores abaixo de $20 \%$. Independentemente do $\mathrm{pH}$, a amostra contendo teor de AF superior a $30,0 \mathrm{mg} \mathrm{L}^{-1}$ não forneceu nenhuma resposta ao teste ELISA, o que refletiu o forte efeito deste material orgânico sobre a eficiência do ensaio. Já em concentrações mais baixas de $\mathrm{AF}\left(6,0 \mathrm{mg} \mathrm{L}^{-1}\right)$, o efeito matriz não é tão significativo, notando-se um pequeno deslocamento das curvas de soluções de AF para a esquerda em relação à curva padrão, com concomitante perda do paralelismo entre as curvas, indicando perda de sensibilidade. Observa-se uma tendência de superestimar a concentração de carbaril (diminuição da absorbância), em vez do esperado decréscimo, possivelmente devido à adsorção do pesticida pelo material húmico. Este comportamento pode ser resultado do efeito matriz proveniente dos elevados teores de matéria orgânica, particularmente em baixas concentrações do analito, podendo levar a resultados falso-posi$\operatorname{tivos}^{18,23}$. Pode-se observar na Tabela 1 , que a sensibilidade do método diminui à medida que aumentam os valores de $\mathrm{IC}_{50}$.
Este fenômeno sugere interações não-específicas entre o material húmico e os reagentes biológicos ${ }^{18}$.

Tabela 1. Valores de $\mathrm{IC}_{50}$ para amostras de carbaril e AFcarbaril em função do $\mathrm{pH}$ e da concentração de AF.

\begin{tabular}{lc} 
Amostra (abrigo da luz solar) & $\mathrm{IC}_{50}(\mathrm{ppb})$ \\
Controle negativo (tampão fosfato) & 0,8 \\
$\mathrm{AF}=30,0 \mathrm{mg} \mathrm{L}^{-1} \quad(\mathrm{pH} \mathrm{8,0)}$ & 12,2 \\
$\mathrm{AF}=30 \mathrm{mg} \mathrm{L}^{-1}(\mathrm{pH} \mathrm{4,0)}$ & 26,5 \\
$\mathrm{AF}=6 \mathrm{mg} \mathrm{L}^{-1} \quad(\mathrm{pH} \mathrm{8,0)}$ & 1,4 \\
$\mathrm{AF}=6 \mathrm{mg} \mathrm{L}^{-1}(\mathrm{pH} \mathrm{4,0)}$ & 2,3 \\
\hline
\end{tabular}

Com a mudança do pH, a distribuição das espécies carregadas nos sítios de ligação do anticorpo e do analito é alterada, variando assim a contribuição das interações eletrostáticas na estabilização do imunocomplexo. Esta situação é complexa pois, pode ocorrer que a constante de afinidade anticorpoanalito, $\mathrm{K}_{\mathrm{a} 1}$, seja maior que $\mathrm{K}_{\mathrm{a} 2}$ (húmico-analito), induzindo o anticorpo a reter o analito. Os outros reagentes, como o traçador enzimático, também podem participar dessas interações ${ }^{23}$. Além disso, alguns autores já demonstraram a existência da relação entre protonação dos grupos carboxílicos presentes nos ácidos fúlvicos e a adsorção de pesticidas. Em pH abaixo de 4,0, os ácidos fúlvicos tornam-se aniônicos mudando sua configuração para uma estrutura "aberta", com o que diminuem as forças de interações entre húmicos e as moléculas do pesticida ${ }^{24,25}$. Com a diminuição do $\mathrm{pH}$, a carga sobre os polímeros das substâncias húmicas dissolvidas é reduzida criando um ambiente apolar ${ }^{26}$.

\section{Influência da luz solar}

Os resultados, da análise do carbaril pela técnica ELISA, mostram a rápida degradação do pesticida carbaril em cerca de 10 min de reação, nas alíquotas contendo AF em comparação com as soluções controle sem AF. Alguns autores creditam este efeito à presença de substâncias húmicas, conhecidas por sua capacidade de atuarem como catalisadores na formação de produtos de degradação em águas naturais ${ }^{7,28}$. Este efeito pode ser observado na Figura 4, onde nota-se uma baixa recuperação do carbaril (cerca de 25\%) em soluções controle somente após 90 minutos de reação.

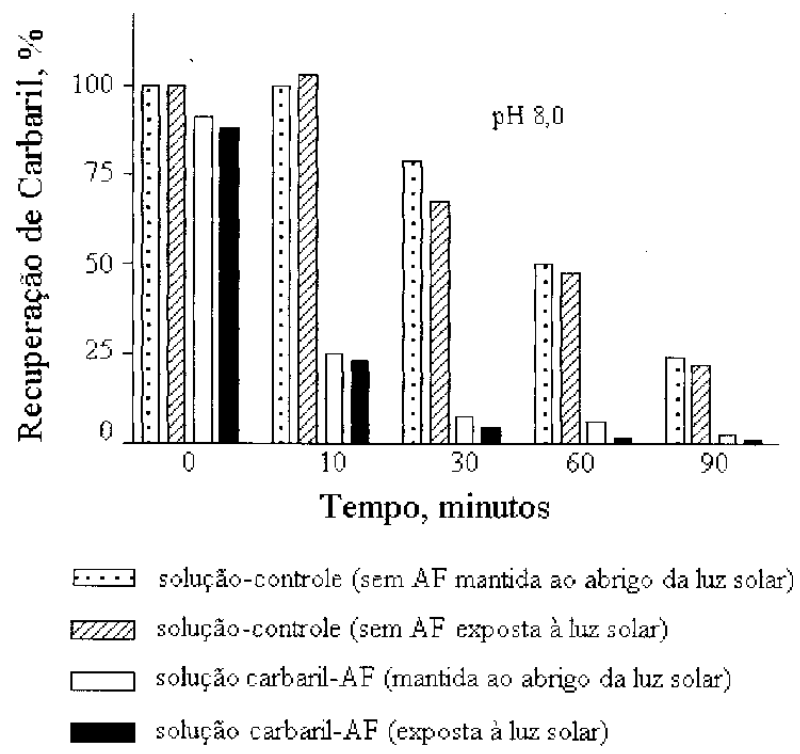

Figura 4. Porcentagem de recuperação de carbaril em amostras controle (sem $A F)$ e em solução de $A F\left(30,0 \mathrm{mg} \mathrm{L}^{-1}\right)$ determinada por ELISA após exposição à luz solar. 
O principal produto da transformação do carbaril é o 1naftol, e a velocidade de degradação do carbaril para gerar esse produto de degradação é acelerada na presença de substâncias húmicas ${ }^{8}$. Tal interpretação veio dos resultados negativos, para carbaril, com os testes ELISA e por CLAE-AD (Tabela 2), após 60 minutos de contato entre o analito e os ácidos fúlvicos.

Tabela 2. Recuperação (\%) de carbaril em soluções de AF (30,0 $\left.\mathrm{mg} \mathrm{L}^{-1}\right)$ por CLAE-AD.

\begin{tabular}{ccc}
\hline Tempo de contato & abrigo da luz solar & luz solar \\
\hline $0 \mathrm{~min}$ & 100 & 100 \\
$10 \mathrm{~min}$ & 100 & 25 \\
$30 \mathrm{~min}$ & 50 & n.d \\
$90 \mathrm{~min}$ & 14 & n.d \\
\hline
\end{tabular}

n.d = não-detectado.

Na Tabela 2 estão listados os valores de recuperação de carbaril obtidos por CLAE-AD em amostras controle (sem AF) e soluções contendo AF. Ficou evidente que o tempo de contato do pesticida com o material húmico e a presença de luz solar aceleraram a velocidade de degradação do composto. Devido ao elevado teor de AF na água analisada, a transformação do princípio ativo, dando origem ao seu principal metabólito, o 1-naftol, foi extremamente rápida.

A forte interação carbaril-AF, que propiciou a sua degradação rápida, explica a presença do 1-naftol observada nas amostras que continham o material húmico, analisadas após esse período. A Figura 5 mostra os cromatogramas do carbaril e 1naftol de uma amostra contendo AF após 30 minutos de contato e protegida da luz solar. Ainda nesta figura pode-se notar que o pico referente ao 1-naftol é mais expressivo que o pico do carbaril indicando, portanto, que metade do carbaril havia se decomposto nesse período. Resultados semelhantes foram observados por Bertrand e Barceló $^{8}$, que sugerem que a degradação do carbaril, tanto no solo quanto na água, está associada à presença de luz solar e de bactérias, além do fato de estar fortemente ligado à matéria orgânica, o que favorece a sua rápida degradação. Ainda segundo esses autores, o tempo de meia-vida desse pesticida depende das condições ambientais ( $\mathrm{pH}$ do meio, temperatura, presença de luz, chuva, etc.), e pode variar de 7 dias em solos aeróbicos, até 28 dias, em solos anaeróbicos ${ }^{28}$. Na água, a degradação está mais diretamente relacionada à concentração de matéria orgânica e tal efeito foi comprovado no presente estudo.

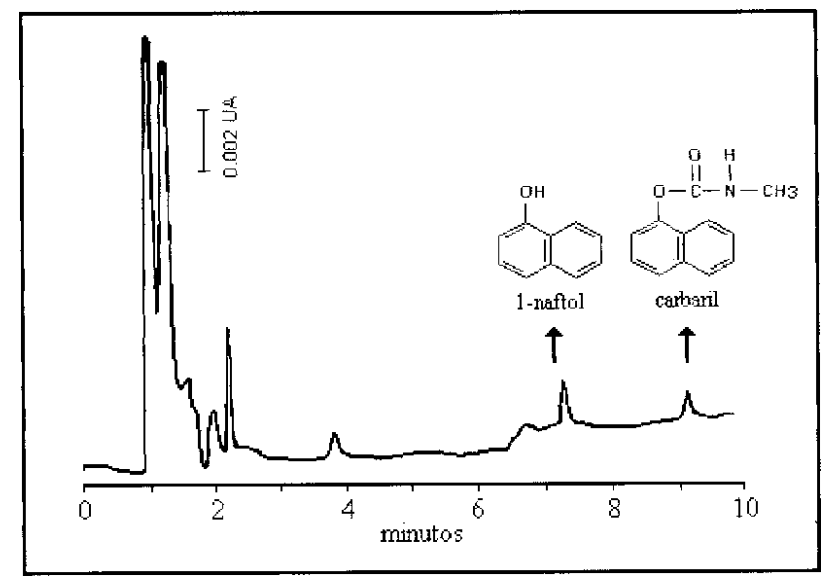

Figura 5. Cromatograma do carbaril e 1-naftol utilizando mistura de

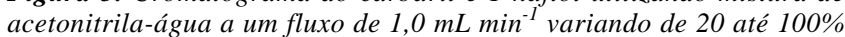
de acetonitrila em $20 \mathrm{~min}$. Amostra contendo $30,0 \mathrm{mg} \mathrm{L}^{-1}$ de AF, após 30 minutos de contato mantida ao abrigo da luz solar e pH 8,0.

\section{CONCLUSÕES}

As técnicas imunoquímicas podem ser alternativas adequadas para a determinação de carbaril em águas naturais, mesmo que contenha altos teores de matéria orgânica. Utilizando-se o teste ELISA desenvolvido para a determinação de carbaril em águas foi observado que os resultados são mais dependentes da concentração de AF que dos valores de $\mathrm{pH}$. Quando presentes em altas concentrações, estes ácidos influenciaram na determinação de carbaril por ELISA, levando à superestimação da concentração do analito, por inibição do sinal analítico (absorbância).

Os resultados aqui obtidos, em soluções contendo $30,0 \mathrm{mg}$ $\mathrm{L}^{-1}$ de AF (Tabela 1), mostraram perda significativa na sensibilidade do método, quando comparados aos valores da solução controle (sem AF). A rápida formação do principal produto de transformação do carbaril, o 1-naftol, pode ter como causa um possível efeito catalisador devido aos teores de AF nas soluções de trabalho. Tal efeito pode ser comprovado pelos resultados negativos para carbaril (CLAE-AD) após $30 \mathrm{minu}-$ tos de contato entre o analito e AF (Tabela 2). O aparecimento de um pico com tempo de retenção característico do 1-naftol, vem reforçar a hipótese da ação catalisadora da presença de AF na degradação do carbaril (Figura 5).

As análises de carbaril por ELISA, podem ser feitas diretamente nas amostras de águas contendo material húmico, sem necessidade de etapas preliminares, bastando fazer 0 ajuste das soluções para $\mathrm{pH}$ entre 8 e 9 e/ou diluição da amostra, até cerca de $6,0 \mathrm{mg} \mathrm{L}^{-1}$ de AF. Tais medidas são suficientes para minimizar o efeito matriz. A eluição da amostra com DMSO causou diminuição da sensibilidade da técnica CLAE-DAD (em torno de $25 \%$ em relação aos cromatogramas obtidos com soluções de padrões dissolvidos em metanol), devido ao alargamento do pico do solvente, logo no início do cromatograma, mas permitiu minimizar a interferência dos AF que absorvem fortemente na região de $200 \mathrm{~nm}$.

Assim, pode-se dizer que a quantidade de matéria orgânica, no caso de AF, presente na amostra de água foi a principal fonte de erro na análise de carbaril, levando à interações nãoespecíficas entre $\mathrm{AF}$ e os reagentes enzimáticos.

\section{AGRADECIMENTOS}

Ilda A. S. Toscano e Gilvanda S. Nunes agradecem ao CNPq a concessão de bolsa de doutorado sanduíche. Os demais autores agradecem ao $\mathrm{CNPq}$ e FAPESP pelo auxílio financeiro.

\section{REFERÊNCIAS}

1. Buffle, J. In Complexation reactions in aquatic systems: an analytical approach; Buffle, J., Ed.; Ellis Horwood; New York, 1990; p 146.

2. Rocha, J. C.; Toscano, I. A. S.; Burba, P.; Talanta 1997, 44, 69.

3. Welhouse, G. J.; Bleam, W. F.; Environ. Sci. Technol. 1992, 26, 959.

4. Thurman, E. M.; Malcolm, R. L.; Environ. Sci. Technol. 1981, 15, 463.

5. Choudhry, G. G. In The handbook of environmental chemistry; Awtzinger, O., Ed.; Springer-Verlag; Berlin, 1982; p 103.

6. Martin-Neto, L.; Vieira, E. M.; Sposito, G.; Environ. Sci. Technol. 1994, 28, 1867.

7. Zepp, R. G.; Schlotzhauer, P. F.; Sink, R. M.; Environ. Sci. Technol. 1985, 19, 74.

8. Bertrand, N.; Barceló, D.; Anal. Chim. Acta 1991, 254, 235.

9. Santos, T. C. R.; Rocha, J. C.; Barceló, D.; Intern. J. Environ. Anal. Chem. 1998, 67, 01. 
10. Barceló, D. In Environmental analysis. Techniques, applications and quality assurance; Barceló, D., Ed.; Elsevier Science Publishers B.V.; Amsterdam, 1993; p 149.

11. Marty, J-L.; Garcia D.; Rouillon, R.; Trends Anal. Chem. 1995, 14, 329.

12. Thomas, D. H.; Beck-Westermeyer, M.; Hage, D. S.; Anal. Chem. 1994, 66, 3823.

13. Gascón, J.; Oubiña, A.; Ballesteros, B.; Barceló, D.; Camps, F.; Marco, M-P.; González-Martínez, M. A.; Morais, S.; Puchades, R.; Maquieira, A.; Anal. Chim. Acta 1997, 247, 149.

14. Gruessner, B.; Shambaugh, N. C.; Watzin, M. C.; Environ. Sci. Technol. 1995, 29, 251.

15. Nunes, G. S.; Toscano, I. A.; Barceló, D.; Trends in Anal. Chem. 1998, 17, 79 .

16. Gee, S. J.; Hammock, B. D.; Van Emon, J. M.; A user's guide to environmental immunochemical analysis. 1994; $\mathrm{EPA} / 540 / \mathrm{R} / 94 / 509$.

17. Aga, D. S.; Thurman, E. M.; Pomes, M. L.; Anal. Chem. 1994, 66, 1495.
18. Dankwardt, A.; Hock, B.; Simon, R.; Freitag, D.; Ketrupp, A.; Environ. Sci. Technol. 1996, 30, 3493.

19. Bushway, R. J.; Fan, T. S.; Food Technol. 1995, 49, 108. 20. Lara, R. J.; Thomas, D. N.; Anal. Chem. 1994, 66, 2417.

21. Marco, M-P.; Gee, S. J.; Cheng, H. M.; Liang, Z. Y.; Hammock, B. D.; J. Agric. Food Chem. 1993, 41, 423.

22. Toscano, I. A. S.; Nunes, G. S.; Barceló, D.; Food Technology and Biotechnology 1998, 36, 245.

23. Toscano, I. A. S.; Gascón, J.; Marco, M-P.; Rocha, J. C.; Barceló, D.; Analusis 1998, 26, 130.

24. Wang, Z.; Environ. Sci. Technol. 1992, 26, 560.

25. Senesi, N. In Organic substances in soil and water: natural constituents and their influences on contaminant behaviour; Beck, A. J.; Jones, K.; Hayes, M. H. B.; Milgelgrin, U., Eds.; Royal Society of Chemistry; Cambridge, 1993; p. 73

26. Gauthier, T. D.; Seltz, W. R.; Grant, C. L.; Environ. Sci. Technol. 1987, 21, 243.

27. Minero, C.; Pramauro, E.; Pelizzetti, E.; Chemosphere 1992, 24, 1597.

28. Wauchope, R. D.; J. Environ. Qual. 1978, 7, 459. 